\title{
FRAY ALONSO DE LA VERACRUZ Y EL DERECHO ALTERNATIVO
}

JESÚS GÓMEZ SERRANO

Departamento de Historia/UAA

Jesús ANTONIO dE LA TORRE RANGel, Alonso de la Veracruz: amparo de indios. Su teoría y práctica jurídica, Aguascalientes, UAA, 1998, 408 pp.

D. ebo iniciar mi reseña confesando que no soy abogado, ni teólogo, ni especialista en los temas que le interesan a Jesús Antonio de la Torre en su libro. Soy un historiador especializado en el siglo XIX a quien sus pesquisas en los archivos le han ayudado a conocer medianamente bien la región de Aguascalientes. Al preparar este comentario advertí una vez más que el nuestro es un medio de especialistas que poco o nada sabemos de los temas que no están en el centro de nuestra atención. Al parecer hemos superado la época de los "todólogos", aquellos profesores que sabían un poco de todo pero que hablaban con una suficiencia capaz de disimular las dudas e impresionar a los incautos. Ahora el gran peligro que nos asecha tiene un origen muy diferente: la especialización, esa característica de nuestro medio académico que nos obliga a saber mucho de cosas muy pequeñas, convirtiéndonos al mismo tiempo en ignorantes de todo lo demás. La especialización en sí misma es buena, pues permite el estudio con profundidad de temas que habían sido sistemáticamente ignorados, pero resulta nociva desde el momento en que inhibe el diálogo entre los académicos y los convierte en dueños y señores de pequeñas fortalezas impenetrables. Creo que tenemos la obligación de cultivar con el mayor esmero nuestro propio jardín, pero que debemos también asomarnos al del vecino, compartir sus esfuerzos y celebrar sus logros.

Por ello quiero agradecer la invitación que se me hizo para comentar el libro de 
Jesús Antonio de la Torre. Víctima o cómplice de ese sistema partidario de la especialización, me he visto obligado a acercarme a temas, épocas y personajes sobre los que poco o nada sé. Tal vez sea sólo una gota de agua en el pozo sin fondo de mi ignorancia, pero en sí misma es muy valiosa la ocasión que se me presenta para intercambiar opiniones e iniciar, como historiador especializado en temas regionales, un diálogo con un abogado que en éste y otros libros se ha interesado en la historia y en el desarrollo histórico del pensamiento jurídico.

La trayectoria como autor de Jesús Antonio de la Torre es larga y merece ser apreciada en su conjunto. Hombre comprometido vivencialmente con sus ideas, se ha dedicado con esmero, paciencia y consistencia admirables, durante casi veinte años, al estudio del derecho y de la práctica jurídica desde la perspectiva de los marginados. Entre El derecho que nace del pueblo, publicado en 1985 por el Centro de Investigaciones Regionales de Aguascalientes, El uso alternativo del derecho por Bartolomé de las Casas, publicado por la Universidad Autónoma de Aguascalientes en 1991, y el libro que hoy reseñamos, consagrado al estudio de la vida y la obra de un fraile agustino que con toda justicia fue calificado por Diego Basalenque como "amparo de los indios", hay lazos de continuidad que se disciernen con facilidad.

Estos tres títulos no representan más que la tercera o la cuarta parte de la obra de Jesús Antonio de la Torre, pero indican muy bien la línea en la que se han orientado sus esfuerzos. De espaldas a un medio profesional en el que se ha entronizado un criterio formal y estrecho de la justicia, de la Torre se ha empeñado en demostrar que es posible una práctica alternativa del derecho y que en la tradición hispanoamericana hay ejemplos muy meritorios de esa práctica. En contra de Friedrich Hayek, quien ha postulado que "a la justicia no le importan los resultados de las transacciones, sino tan sólo si esas transacciones son en sí justas", de la Torre recuerda que desde el siglo XVI un fraile novohispano sostenía que la justicia no era sólo formal sino también material, lo que quiere decir, por ejemplo, que en un contrato de compraventa el interés jurídico radica, a la vez, en la perfección formal del contrato y en la equidad del intercambio. Hablando de los pueblos de indios y de las tierras que con engaños vendían a los españoles, Alonso de la Veracruz sostiene con firmeza que esos contratos eran injustos y nulos en derecho porque privaban a los pueblos de su sustento y redundaban en su detrimento (pp. 199-204). 
Alonso Gutiérrez, el personaje central del libro reseñado, nació en 1507 en Caspueñas, dentro de la diócesis de Toledo, en el seno de una familia acomodada. Estudió humanidades en la Universidad de Alcalá de Henares, que hacía poco había sido fundada por el cardenal Jiménez de Cisneros. Después pasó a la Universidad de Salamanca, que por entonces era la de mayor prestigio en toda la península, y ahí estudió artes y teología. Se distinguió entonces como uno de los alumnos predilectos del gran Francisco Vitoria, de quien al parecer obtuvo el grado de maestro. La feliz y rara conjunción en ese estudiante de "mucho estudio con mucho ingenio", auguraban para él grandes logros académicos y la protección de los príncipes de la Iglesia. Sin embargo, Francisco de la Cruz, un fraile agustino que buscaba misioneros para là evangelización americana, se cruzó en su camino y de alguna manera se las ingenió para convencerlo de viajar a las Indias como misionero.

Como dice de la Torre, es muy difícil saber a ciencia cierta qué motivó a Alonso Gutiérrez "para cambiar su promisoria carrera magisterial en Salamanca por la sencilla y poco recompensada enseñanza del evangelio a los indios" (p. 10). Lo cierto es que se embarcó en Sevilla y du- rante la travesía atlántica fue convencido de tomar los hábitos de la orden de San Agustín. Al tocar tierra, Alonso Gutiérrez se convirtió en Alonso de la Veracruz, en recuerdo del lugar en el que tomaba los hábitos y del padre Cruz, que lo había convertido a su causa. Llegó a la ciudad de Míxico en julio de 1536 y un año después, en el convento de Santa María de Gracia, hacía solemne profesión de votos. En atención a sus prendas intelectuales y morales, fue de inmediato nombrado maestro de novicios.

En 1540 fray Alonso de la Veracruz se instaló en Tiripetío, donde los agustinos tenían abierto un colegio de altos estudios en el que atendían por igual indios y españoles. Ahí conoció a Antonio, hijo del Calzontzi, el rey de los tarascos torturado y quemado vivo por el sanguinario Nuño de Guzmán. Citando a Antonio Gómez Robledo, de la Torre hace notar que la obra toda de la conquista está contenida en este paradójico episodio, pues las heridas provocadas por el cruel verdugo fueron curadas por la caridad y mansedumbre de fray Alonso (p. 69). En 1542, al dejar Vasco de Quiroga la diócesis de Michoacán con el propósito de participar en el concilio de Trento, fray Alonso se quedó temporalmente al frente de la diócesis y dio muestras de su prudencia y capacidad de gobierno. En 1553 se le ofreció el obispado 
de la diócesis de León, en Nicaragua, pero "por humildad" lo rechazó. Ese mismo año, al abrirse las puertas de la Universidad de México, se asignaron a fray Alonso dos cátedras, lo que le permitió retomar el hilo de los estudios que había interrumpido al dejar la Universidad de Salamanca. Consagrado casi por completo al estudio y la meditación, publicó algunas obras e inició otras, sin abandonar nunca su tenaz defensa de los derechos de los indios. Ello le acarreó numerosas dificultades y fue una de las razones por las que se vio obligado a regresar a España, donde permaneció hasta mediados de 1573. De esta prolongada estancia en la península se sabe realmente poco, aunque está fuera de dudas el hecho de que el agustino no abandonó la causa de los indígenas americanos.

Otra cosa que se sabe de cierto es que se dedicó a reunir libros para las bibliotecas mexicanas. Eran tantos los volúmenes con los que se hizo a la mar -"más de sesenta cajones de ellos", dice Basalenque- que fue necesario que en el barco se acondicionase una bodega especial en la que pudiera almacenar la preciada carga. Intelectual al fin, había sufrido en carne propia la casi absoluta falta de libros que padeció la Nueva España durante la primera mitad del siglo XVI, carencia que él contribuyó a llenar. Uno de sus más importantes biógrafos lo considera el funda- dor y principal animador de la primera biblioteca que hubo en todo el continente americano, circunstancia que por sí sola le aseguraría un lugar distinguido en las páginas de la historia (pp. 72-73).

En 1575 fray Alonso fue electo por cuarta vez superior provincial de su orden y en ese mismo año abrió el colegio de San Pablo, en la ciudad de México. Desde entonces hasta el año de su muerte -1584- dedicó buena parte de su tiempo al estudio y a preparar diversas ediciones de sus obras. Como señaló alguno de sus biógrafos, era un hombre "de poco dormir y continuo estudio", lo que atestiguan sus tratados, pero también las anotaciones y marcas que dejó en los libros de las bibliotecas en las que tuvo oportunidad de trabajar.

\section{DEFENSA DE LOS DERECHOS}

DE LOS INDIOS

Una de las vetas del pensamiento de fray Alonso que más le interesan a Jesús Antonio de la Torre es la que corresponde a su defensa de los derechos de los indios; la obra del agustino, nos dice, "se inscribe de lleno en la tradición teórica de los derechos humanos hispanoamericana" (p. 90). A partir del reconocimiento de la dignidad humana, que tiene un alcance universal, emprende la defensa de los naturales, de 
sus pueblos y del derecho de las comunidades a sus tierras. Este último asunto es crucial, pues como señaló hace ya muchos años José Miranda, la tierra era para los indios el cemento que los cohesionaba y hacía posible la vida de los pueblos. Particular interés reviste su alegato sobre el carácter no obligatorio que tenían los diezmos para los indios; más que jurídico o legaloide, el alegato de Veracruz es humanista, pues considera que esa exigencia era injusta y traía aparejada la explotación de las mujeres y los niños, quienes se veían obligados a trabajar para hacer esos pagos. En un pasaje citado por de la Torre, fray Alonso denuncia que las mujeres tejían sus lienzos, en los obrajes de los españoles, "con enorme trabajo y gran peligro para su cuerpo y para su alma". Se trataba de cosas que le constaban personalmente y no podía callar: las mujeres, "encerradas por fuerza y violencia”, trabajaban sin parar, amamantando al mismo tiempo a sus criaturas y resistiendo como podían los accesos de lujuria de sus patrones. En forma inequívoca, adoptando sin vacilaciones ni disimulos el punto de vista de los oprimidos, el agustino emprende aquí la defensa de los derechos humanos. Esta conclusión es tan categórica que de la Torre no duda en afirmar que tales derechos constituyen la base misma "de la teoría y la praxis jurídicas de Veracruz” (pp. 89-90).
La defensa de los derechos de los indios es el tema central de una de las relecciones más importantes de fray Alonso: $D e$ dominio infidelium et iusto bello, redactada con el propósito de ser leída en la Universidad de México en la primavera de 1554. En ella se establece que las relaciones entre indios y españoles deben darse sobre una base de justicia y que los pueblos tienen plenos derechos a la posesión y el usufructo de sus bienes. Que la tierra es propiedad de los pueblos es para Veracruz "una verdad jurídica inobjetable”. Citando a Silvio Zavala, de la Torre afirma que este tratado hace del agustino un precursor del derecho agrario (pp. 167169, 182.).

En otro pasaje, de la Torre intenta un "catálogo mínimo" de los derechos a los que se refiere fray Alonso en su obra, o bien que tuvo oportunidad de defender como catedrático de la Universidad y como protector de los indios. De ese catálogo (pp. 125-138) destacó el derecho de los indios a la libertad, lo que en aquella época y en ciertos ambientes implicaba una auténtica declaración de guerra, pues los grandes encomenderos, los mineros y los dueños de trapiches asumían por interés que los indios eran esclavos o bien siervos de los que podían abusar a su antojo. Sobresale también el derecho a la libertad de opinión y cátedra, en cuya defensa 
fray Alonso se mostró inflexible; la suya fue una postura de absoluta independencia intelectual frente a las autoridades virreinales e incluso frente a la temible jerarquía eclesiástica, lo que, como veremos enseguida, le acarreó grandes problemas. En cuanto al derecho de propiedad, no deja de reconocerlo, pero no en el sentido "exclusivo y excluyente" defendido por el individualismo liberal, sino reconociendo la función social de la propiedad y las obligaciones que con la comunidad tienen los propietarios. Por último menciono el derecho de resistencia frente a los abusos del tirano; siguiendo a San Agustín, fray Alonso lo reconoce en forma abierta y plena, siempre y cuando "su ejercicio no tuviera consecuencias peores que las perturbaciones que el régimen tiránico ocasionaba".

El tratado De decimis, en el que fray Alonso defiende la idea de que los indios no tienen obligación de pagar tributo, reviste para el historiador un interés adicional, pues provocó un enfrentamiento entre su autor y Alonso de Montúfar, el segundo arzobispo de México. Este último era un hombre viejo, dominado por cierta "acrimonia senil" e influido en exceso por una partida de clérigos seculares a los que el muy ortodoxo padre Cuevas no duda en ubicar entre "lo peorcito de España". Al parecer, Montúfar profesaba un odio singular a los agustinos, por lo que no debe extrañar su enfrentamiento con fray Alonso. Lo que queremos destacar es que el agustino creía verdaderamente en la libertad de cátedra y que no dudó en defender sus ideas ante el prelado más importante que había en toda la Nueva España. Este enfrentamiento fue una de las razones que lo obligaron a regresar a España en 1562 (pp. 263-264, $273,306)$.

\section{AQUELLOS FRANCISCANOS}

Sobre Juan de Aora, Juan de Tecto y Pedro de Gante, los primeros frailes franciscanos que desembarcaron en la Nueva España (agosto de 1523) e iniciaron esa empresa formidable que fue la "conquista espiritual" de la Nueva España, de la Torre hace algunas precisiones interesantes. Nos recuerda su origen flamenco y la forma en la que sus nombres y apellidos originales fueron castellanizados, a lo que conviene agregar que el haber sido educados dentro del "refinado ambiente intelectual de Flandes", en los monasterios reformados de la orden franciscana, les permitió entrar en contacto con el pensamiento de Erasmo. Sin lugar a dudas asimilaron las ideas y los ideales del gran sabio de Rotterdam, lo que es muy claro en el modelo de evangelización que propusieron y en las características de mu- 
chos de los colegios que fundaron, como por ejemplo el de la Santa Cruz, en 1536.

Juan de Tecto era un "sacerdote honrado" que por desgracia murió poco después de desembarcar en las costas veracruzanas. Por su parte, Juan de Ahora era un "varón doctísimo", el más sabio de los europeos que hasta entonces habían emigrado a América, y a la vez un hombre extremadamente humilde. Había sido confesor de Carlos V y profesor de teología en la Universidad de París durante 14 años, a pesar de lo cual, cuando se le preguntó qué hacía en las Indias, respondió con fina ironía que aprendía la teología "que de todo punto ignoró San Agustín”. Se refería por supuesto al náhuatl, lengua que él y sus compañeros llegaron a dominar. En cuanto a fray Pedro de Gante, autor de una obra humana "muy hermosa", como dice Ricard, conviene recordar que era también un hombre muy modesto, que "por humildad nunca quiso ser ordenado". En la escuela de San José, por él fundada, 2 mil niños indígenas "aprendían canto, música, artes manuales y latín y se preparaban como catequistas para después difundir en los pueblos lo que se les había enseñado". Fray Pedro de Gante murió en 1564, sin haber regresado nunca a Europa, ocupado por completo en la evangelización de los naturales. ${ }^{1}$

En cuanto al grupo de franciscanos encabezado por fray Martín de Valencia y conocido como los doce apóstoles, a cuyo arribo se refiere de la Torre, tal vez no sea ocioso recordar que eran también religiosos reformados, educados en la provincia franciscana observante de San Gabriel de Extremadura, de la cual Valencia había sido primer provincial. Menos instruidos y refinados intelectualmente que los flamencos, los doce eran partidarios de una religiosidad sencilla y a la vez radical. Herederos informales de los movimientos místicos que se desarrollaron en la península a partir del siglo XIII, tenían por norma asimilar las costumbres y el modo de hablar de las gentes de los lugares en los que se establecían. Su antiintelectualismo y la forma entusiasta en la que vivían la espiritualidad popular les había restado adeptos en España, sobre todo entre los altos mandos de la jerarquía eclesiástica, lo que no dejó de pesar en su decisión de emigrar a la Nueva España. Lo que es cierto, nos recuerda Sonia Corcuera, es que flamencos o extremeños, refinados o populistas, todos estos primeros misioneros franciscanos coincidían en el propósito fundamental de "hacer realidad

1. Las referencias adicionales a estos frailes provienen de Sonia Corcuera de Mancera, El fraile, el indio y el pulque. Evangelización y embriaguez en la Nueva España (1523-1548), México, Fondo de Cultura Económica, 1997, pp. 129-130. 
los ideales del cristianismo primitivo mediante una vida en que destacaban la piedad, la pobreza y la caridad". 2

En cuanto a fray Juan de Zumárraga, primer obispo de México, de la Torre precisa que su tenaz defensa de los derechos de los indios le costó grandes dificultades con los funcionarios de la primera Audiencia, los cuales lo conminaron a desoír las quejas de los naturales y lo amenazaron con el destierro, la prisión e incluso la muerte. Por si ello fuera poco, los indios que se acercaron a Zumárraga en busca de amparo fueron ahorcados, pero ello no lo hizo desistir ni mucho menos deshonrar el cargo de "protector de indios" que el rey le confirió.

La tenacidad y verticalidad de Zumárraga se entienden mejor si se recuerda que durante muchos años fue guardián del monasterio de Abrojo, en Valladolid, lugar desde el que atestiguó la "revolución espiritual" que desataron en Europa los textos de Erasmo. Era ya un hombre entrado en años cuando cambió la quietud de su monasterio vallisoletano por la agitación y las incertidumbres de la vida en el nuevo continente. En 1532, cuando regresó a España para ser consagrado obispo, se convirtió en un abierto defensor de los indios y en un implacable crítico de los abusos cometidos por los conquistadores.

2. Ibid., p. 131 .
Entre octubre de 1534 y junio de 1548 -fecha de su muerte- consagró todas sus energías a la propagación entre los indios de la doctrina cristiana. El suyo es un caso en cierta forma curioso, pues no aprendió lenguas indígenas ni se dedicó en forma directa a la evangelización, pese a lo cual la historia lo ha consagrado como el primer gran divulgador del cristianismo entre la población aborigen. En los catecismos o doctrinas que publicó son evidentes los ideales humanistas que había abrevado de la filosofía erasmiana, e incluso la abierta admiración que sentía por el autor del Elogio de la locura. Ambos eran partidarios de una práctica religiosa fundada "más en el amor que en el temor" y de la evangelización de los indios como obra no de la imposición, sino del convencimiento. $^{3}$

\section{TRADICIÓN AUTONÓMICA}

DE LOS AYUNTAMIENTOS

Me llamaron la atención los comentarios que hace de la Torre sobre los primeros ayuntamientos formados en la Nueva España, que como se sabe le dieron sustento legal a muchas de las empresas iniciadas por el conquistador Hernán Cortés.

3. Ibid., p. 171-177. 
Dice el autor que

los ayuntamientos demostraron así la fuerza inicial con que nacieron en Nueva España, rescatando su vieja tradición libertaria y autonómica del derecho foral del medioevo castellano; e hicieron valer una tradicional institucion jurídica, también del derecho de Castilla, conocida con la fórmula del "Obedézcase, pero no se cumpla"...

Según Anselmo Carretero ${ }^{4}$ esa fórmula tiene su origen'en Guipúzcoa, una de las provincias del País Vasco. Hacia el año 1200, disgustados con el monarca navarro, su antiguo señor, los guipuzcoanos le ofrecieron a Alfonso VIII de Castilla el señorío de su estado, pero obtuvieron de los monarcas castellanos el compromiso de "respetar puntualmente la constitución del estado". Este acuerdo constituye la base del pase foral, es decir, la facultad de la asamblea legislativa o Juntas Generales de Guipúzcoa "para rechazar o negar el pase a las peticiones o mandatos de la corona que consideraban contrarios a sus fueros". Este derecho se ejercía precisamente mediante la fórmula se obedece, pero no se cumple, a la que se aparejaba, como indica de la Torre, el recurso de suplicación,

4. Anselmo Carretero y Jiménez, Los pueblos de España. (Introducción al estudio de la nación española), México, ENEP Acatlán/unam, 1980, pp. 108-110. "que tenía por objeto solicitar del rey la revocación o modificación de sus disposiciones".

\section{BARTOLOMÉ DE LAS CASAS \\ Y FRAY ALONSO}

Como era de esperarse en quien le dedicó una obra a fray Bartolomé de las Casas, de la Torre no pudo resistir la tentación de explorar las posibles relaciones de amistad e intelectuales que hubo entre el ilustre dominico y fray Alonso de la Veracruz. Prometeo Cerezo de Diego, uno de los más conocidos y autorizados estudiosos de la obra de este último, había adivinado que entre esos dos grandes defensores de los indios "había una relación estrecha", pero él mismo descartaba la hipótesis alegando diferencias de edad, de formación intelectual y hasta de "temperamento". Jesús Antonio de la Torre nos recuerda que en realidad sí hubo afinidad personal y relaciones entre fray Bartolomé y fray Alonso, tanto en la Nueva España como en la península. Investigaciones recientes indican que entre fines de 1562 y mediados de 1566 las relaciones entre ellos fueron muy estrechas, hasta el punto de que cuando murió el dominico, fray Alonso se hizo cargo de sus asuntos. Hay incluso una obra inédita de Las Casas que fue redactada en colaboración con fray 
Alonso y en cuyo manuscrito se conservan 20 notas autógrafas de este último. Todo ello le permite afirmar a de la Torre que las ideas y la práctica jurídica de Veracruz se vieron enriquecidas "por su asociación con Las Casas" (p. 366).

\section{DOS OBSERVACIONES CRÍTICAS}

Antes de terminar tal vez no resulte demasiado imprudente hacer una observación sobre las encomiendas y sobre la forma en la que Jesús Antonio de la Torre las estudia en su libro. Me parece que en este punto le da demasiado peso a la argumentación jurídica, en detrimento de las consideraciones de carácter histórico que exige una materia tan controvertida. De hecho me parece sumamente discutible su conclusión o premisa en el sentido de que la encomienda era la base misma "del funcionamiento social y económico de la Nueva España", como reza el título de uno de los apartados del capítulo 2 (p. 23). $\mathrm{El}$ gran problema consiste en que la demostración de una tesis así exige otras muchas pruebas, aparte de las estrictamente jurídicas. No discuto la utilidad del conocimiento de los orígenes legales de la encomienda, pero me parece que no es suficiente para determinar su funcionamiento como institución económica y social. En la historia de México hay muchos ejemplos que muestran la forma en la que las instituciones se adaptan, se transforman y eventualmente acaban siendo algo muy distinto de lo que fueron en un principio o de lo que soñaron los juristas que las idearon. Más que averiguar la improbable medida en la que las leyes dan cauce a la historia, debemos preguntarnos por la capacidad de los hombres de ajustar la normatividad a las siempre cambiantes circunstancias de tiempo y lugar. Al respecto cabe recordar la sabia advertencia de Witold Kula sobre los peligros de las fuentes históricas de carácter normativo, pues si se aficiona uno en exceso a ellas fácilmente acaba concluyendo como fueron las cosas a partir de documentos en los que simplemente se dice como debieron ser. ${ }^{5}$

En este mismo tono crítico, pero respetuoso y propositivo, añado mi impresión de que el método de exposición escogido por Jesús Antonio de la Torre tal vez no sea el más adecuado. En algunos capítulos se aprecia que la argumentación se prolonga demasiado, perdiendo con ello fuerza el hilo conductor del discurso y las ideas rectoras. Creo que el libro y la exposición en su conjunto ganarían mucho si se prescindiera de algunas transcripciones que resultan demasiado largas y rei-

5. Witold Kula, Teoría económica del sistema feudal, México, Siglo XxI Editores, 1979, p. 47. 
terativas; ahí debieran verse la mano y el criterio del escritor/artesano, que distingue lo esencial de lo accesorio y plantea sus argumentos de la manera más económica y clara posible. Hace ya muchos años, otro hombre "de poco dormir y continuo estudio", aunque no piadoso, trazó una distinción crucial entre el método de investigación, que pugna por "apropiarse pormenorizadamente de su objeto, analizar sus distintas formas de desarrollo y rastrear su nexo interno", y el método de exposición, que es por definición partidario de la llaneza y la economía de medios. Carlos Marx, a quien debemos esta observación, añadía que cuando el autor lograba su propósito los lectores podrían tener la impresión de estar "ante una construcción apriorística”. Sin embargo, esa facilidad es sólo aparente, pues en realidad es el resultado de una ardua elaboración. Como el mismo Marx dijo, "en la ciencia no hay caminos reales, y sólo tendrán esperanzas de acceder a sus cumbres luminosas aquellos que no teman fatigarse al escalar por senderos escarpados". ${ }^{6}$ Jesús Antonio no teme los "senderos escarpados", pero bien pudiera indicarnos a sus lectores los atajos que nos permitieran evitarlos.

6. Carlos Marx, El Capital, tomo I, vol. I, México, Siglo XxI Editores, 1978, pp. 19 y 21.

\section{Comentario FINAL}

Para concluir quiero insistir en algo que resultará obvio para todos aquellos que conocen a Jesús Antonio y han leído sus obras. En cierto sentido, estudiar ha sido para él forjarse un linaje espiritual e intelectual. En su mayor parte, su obra jurídica está consagrada al estudio de personajes de los que se sabe y se siente muy cercano. Las ideas de fray Alonso son las suyas propias, como también lo son las de fray Bartolomé de las Casas, al que no por accidente le dedicó ya un libro y varios artículos. Quiero subrayar que no se trata de un parentesco meramente intelectual: la afinidad es moral, tiene que ver tanto con las ideas como con la actitud asumida ante la práctica del derecho. Eso es lo que justifica la alusión a Amilton Bueno, el juez brasileño que busca leyes "efectivamente justas, comprometidas con los intereses de la mayoría de la población, realmente democráticas" (p. 320). Lo que Jesús Antonio nos está diciendo es que, por fortuna, la antorcha que encendieron aquellos grandes defensores de los indios en el siglo XVI sigue viva en la práctica alternativa del derecho con la que están comprometidos los jueces gauchos del sur de Brasil... y algunos abogados de Aguascalientes. 중 
